\title{
What if we also apply Bioethics Principles outside Healthcare?
}

\section{Hoffman DP*}

Associate Professor, Department of Ethics and Health Policy, Maria College, USA

*Corresponding author: David P Hoffman, Associate Dean for Academic Initiatives and Government Affairs, Department of Ethics and Health Policy, Maria College 700 New Scotland Ave, Albany, New York 12208, USA, Tel: 5183667544; Email: dhoffman@mariacollege.edu

\section{Commentary}

Volume 4 Issue 4

Received Date: October 06, 2021

Published Date: October 27, 2021

DOI: $10.23880 / a b c a-16000205$

\section{Commentary}

During the past few months there have been numerous government interventions to address the Covid19 Pandemic. Some of these follow the advice of public health professionals and the latest science on the topic, others sadly are political stunts that have resulted in worse outcomes for those impacted and often people they contact. One recent CDC study showed conclusively that the science-based policy choice on masking in schools was significantly more effective at avoiding disease that the politically motivated "bans" on mask mandates [1]. Health officials, hospital officials and provider groups continue to wonder and worry - where do we go from here?

I posed this question to some colleagues and had a discussion proposing that rather than the influence coming from political forces to health - what of we applied the principles of bioethics to public policy - or even citizenship?

When I think of healthcare ethics the frame of reference I use is Beauchamp and Childress, Principles of Biomedical Ethics $8^{\text {th }}$ (Edn.) [2]. These authors offer us a balanced approach with four primary principles (with this author's interpretation). These are: Autonomy Respecting the individual and the informed choices they make regarding their own health; Beneficence To aim for good, for outcomes that are positive for all those we serve; Non-Maleficence "Do no harm", to avoid harm or risk to self or others whenever possible; and Justice To work toward fairness in all aspects of care (including access) for individuals and populations.

Let's imagine if you will that all public policy related to our individual and collective health was designed through the lens of these principles and then implemented through these principles. I have had conversation with leaders at three separate institutions of higher education regarding their "vaccine mandate" policies. All three saw this as one step to assure maximum safety while moving toward "normalcy" in higher education to the degree possible. Coincidentally all three told versions of the same story when I asked about student reaction to the requirement. All three included comments like: they didn't understand that not being vaccinated caused risk to their children and family members (especially adults with chronic diseases); they didn't understand they would need to be vaccinated to complete their internship/practicum/clinical experience; they didn't understand that the science is clear that the vaccine is both safe and effective especially regarding fertility/pregnancy/ breastfeeding [3]. This routinely resulted in students becoming fully vaccinated quickly. When we think about the principle of autonomy, the emphasis isn't on individuals choosing "what they want", but making informed choices. When these once resistant students were fully informed the resistance dissipated quickly.

Interestingly the second principle, beneficence, is often absent from much of the public dialogue about policy around the pandemic. We hear much about "my rights", but not so much about how we care for those in our community or even awareness that sometimes exercising those "rights" can cause significant risk to others, especially others we are in close contact with each day. I like to imagine a world where the first question is "how can we accomplish this and help the most people?". People who aspire to work in healthcare study these principles and learn that for many of them this desire to do good for others is a primary motivator shouldn't we look for that quality in public officials as well? What if that was part of the preparation for citizenship in schools?

The third principle, non-maleficence, is commonly known as "do no harm". This seems like it should be part of our 
common sense approaching public policy (and citizenship as well). How can we grow and thrive as individuals, families, groups and communities if some of our planned actions are harmful to others. In public health we see lots of examples of policies that aim to prevent and avoid harm. We don't allow young children to use tobacco or alcohol, require use of seatbelts and other auto safety devices, limit speed for drivers etc. These "Do no harm" policies are part of the fabric of our lives we often take for granted. When faced with the challenge of a pandemic we might do well to include this in the calculation on what policies to use and require of others.

The final principle, justice, looks toward our policies and procedures to be fair in access and implementation. In the Covid19 context we see that policies are widely diverse in their development and implementation. This lack of justice in the development process precludes fairness in implementation. We see this in the school mask mandate studies mentioned earlier. In some places masks are required and strategies are employed to limit any interference in socialization or learning by use of masks. This contrasts with places where politically based policies (not related to science) prohibit mask mandates specifically restricting use of a strategy that studies have proven works. One important factor here is addressing the plethora of sources of misinformation, rumors, un-informed opinions, and direct falsehoods. These sites and the individuals behind them cause tremendous harm through creating misplaced doubt of real science (sometimes in the name of "free speech"). None of these principles support the provision of falsehoods and justice calls on us to identify these and eliminate them when possible to provide a free-fair exchange of ideas based on facts and fully informed individuals and decision makers who can use facts to make the best possible individual and collective decisions. Understand that a principled approach calls on us to respect divergent opinions but only when based on facts and reality. Several web-sites are dedicated to sorting out myths and facts [4].

When we look back on these times there will be a growing body of evidence of the death and medical suffering that occurred that we already know were preventable. There will also be an expanding set of definitions of the related suffering that was preventable. This last comment relates to the heart wrenching stories we've all shuddered when we read of small children who will never experience a life cut short by preventable Covid19, children who will grow up never knowing a parent who refused a vaccine and died from Covid19, and the list goes on.

My point today is that we need to hold one another and our leaders to the standards we're called to by the principles of bioethics I've described. Questions we should always ask include:

- Is autonomy being exercised in a fully informed manner?

- Is the intent of that policy, action, or decision not to act based on a goal of doing good for all impacted?

- Do leaders in society, communities, institutions, groups and families strive to avoid all preventable harm?

- Are the policies and actions put in place just and fair to the populations impacted?

We've seen leaders emerge both in public policy and the public sphere on-line at all levels of culture and social interaction. These individuals and the groups they serve and represent need to be held to these same principles and focus on the questions I've listed. We already have evidence that we can do better. In order to accomplish this we need to look beyond our individual desires, remember we are all part of various groups and communities and our decisions (especially in a pandemic) impact not just ourselves but all those we interact with and those they interact with -this is the nature of contagion, it continues even after we are present through those we have contacted. We will all benefit if we strive to meet the principles I've described here. We could have prevented more death and bodily suffering than we can accurately describe today. We could also have prevented countless broken family relationships, friendships and other human interactions I won't even attempt to quantify these additional painful outcomes of actions, decisions, and often uninformed/ poorly informed yet strident positions taken in the public sphere.

In conclusion I challenge us to hold ourselves and leaders in our circles including all facets of our lives including work, profession, communities large and small, region and nation responsible to use these principles in how we communicate, relate to one another individually and collectively, and the actions we take in our work and lives together. Let us all go beyond asking the questions and include the integration of principles into all these aspects of our lives. This means using bioethics principles as both a filter in communication and a litmus test for policy. We can then begin to hold decision makers, leaders and public officials responsible to the answers. If we do, we will all be better off as we move to a more community minded society. The irony is that it is in all our self-interest to do this sooner rather than later.

\section{References}

1. (2021) Studies Show More COVID-19 Cases in Areas without School Masking Policies. Centers for Disease Control and Prevention.

2. Beauchamp TL, Childress JF (2019) Principles of Biomedical Ethics, $8^{\text {th }}$ (Edn.), Oxford University Press NY. 
3. (2021) COVID-19 Vaccines While Pregnant or Breastfeeding. Centers for Disease Control and Prevention.
4. (2021) Myths and Facts about COVID-19 Vaccines. Centers for Disease Control and Prevention.

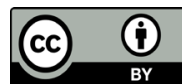

